\title{
Marine microbial communities of the Great Barrier Reef lagoon are influenced by riverine floodwaters and seasonal weather events
}

Florent E Angly, Candice Heath, Thomas C Morgan, Hemerson Tonin, Virginia Rich, Britta Schaffelke, David G Bourne, Gene W Tyson

The role of microorganisms in maintaining coral reef health is increasingly recognized. Riverine floodwater containing herbicides and excess nutrients from fertilizers compromises water quality in the inshore Great Barrier Reef (GBR), with unknown consequences for planktonic marine microbial communities and thus coral reefs. In this baseline study, inshore GBR microbial communities were monitored along a $124 \mathrm{~km}$ long transect between 2011 and 2013 using 16S rRNA gene amplicon sequencing. Members of the bacterial orders Rickettsiales (e.g. Pelagibacteraceae) and Synechococcales (e.g. Prochlorococcus), and of the archaeal class Marine Group II were prevalent in all samples, exhibiting a clear seasonal dynamics. Microbial communities near the Tully river mouth included a mixture of taxa from offshore marine sites and from the river system. The environmental parameters collected could be summarized into four groups, represented by salinity, rainfall, temperature and water quality, that drove the composition of microbial communities. During the wet season, lower salinity and a lower water quality index resulting from higher river discharge corresponded to increases in riverine taxa at sites near the river mouth. Particularly large, transient changes in microbial community structure were seen during the extreme wet season 2010-11, and may be partially attributed to the effects of wind and waves, which resuspend sediments and homogenize the water column in shallow near-shore regions. This work shows that anthropogenic floodwaters and other environmental parameters work in conjunction to drive the spatial distribution of microorganisms in the GBR lagoon, as well as their seasonal and daily dynamics. 
Marine microbial communities of the Great riverine floodwaters and seasonal weather events Tonin 2, Virginia Rich ${ }^{3,4}$, Britta Schaffelke 2, David G Bourne ${ }^{2}$, Gene W Tyson ${ }^{1}$

$9{ }^{1}$ Australian Centre for Ecogenomics, School of Chemistry and Molecular Biosciences, The Uni-

10 versity of Queensland, St Lucia, Queensland, Australia

112 Australian Institute of Marine Science, Townsville, Queensland, Australia

$12{ }^{3}$ Department of Soil, Water and Environmental Science, University of Arizona, Tucson, Arizona,

13 United States of America

$14{ }^{4}$ Current affiliation: Microbiology Department, The Ohio State University, Columbus, Ohio,

15 United States of America

$16{ }^{*}$ Corresponding author: florent.angly@gmail.com 


\section{Abstract}

18 The role of microorganisms in maintaining coral reef health is increasingly recognized. Riverine floodwater containing herbicides and excess nutrients from fertilizers compromises water quality in the inshore Great Barrier Reef (GBR), with unknown consequences for planktonic marine microbial communities and thus coral reefs. In this baseline study, inshore GBR microbial communities were monitored along a 124 km long transect between 2011 and 2013 using 16S rRNA gene amplicon sequencing. Members of the bacterial orders Rickettsiales (e.g. Pelagibacteraceae) and Synechococcales (e.g. Prochlorococcus), and of the archaeal class Marine Group II were prevalent in all samples, exhibiting a clear seasonal dynamics. Microbial communities near the Tully river mouth included a mixture of taxa from offshore marine sites and from the river system. The environmental parameters collected could be summarized into four factors, represented by salinity, rainfall, temperature and water quality, that drove the composition of microbial communities. During the wet season, lower salinity and a lower water quality resulting from higher river discharge corresponded to increases in riverine taxa at sites near the river mouth. Particularly large, transient changes in microbial community structure were seen during the extreme wet season 2010-11, and may be partially attributed to the effects of wind and waves, which resuspend sediments and homogenize the water column in shallow near-shore regions. This work shows that anthropogenic floodwaters and other environmental parameters work in conjunction to drive the spatial distribution of microorganisms in the GBR lagoon, as well as their seasonal and daily dynamics.

\section{Introduction}

Coral reefs are among the most biologically diverse and productive ecosystems on Earth. However, these complex assemblages, often compared to tropical rainforests, are under increasing anthropogenic pressure. Reefs are experiencing a rapid decline due to a combination of local pressures such as overfishing, nutrient enrichment, increased land runoff and sedimentation, and global disturbances such as rises in temperature (Pandolfi et al., 2003; De’ath et al., 2012). The GBR is a World Heritage Area and the largest reef complex in the world, stretching over 2,100 $\mathrm{km}$ along the Queensland coast of Australia. Despite being considered one of the best managed marine areas, the GBR is exposed to nutrient, sediments and pollutant inputs from land-based activities (Schaffelke et al., 2012a, 2013) resulting in a 50.7\% decrease in coral cover over the last 
4727 years (De'ath et al., 2012). Given the fundamental socio-economic role coral reefs have in

48 many countries (food production, tourism, coastal protection) and their ecological value (biodi-

49 versity and productivity), it is vital that these ecosystems are better understood and protected.

50 Microorganisms are a diverse group of unicellular organisms that form the base of the marine

51 food chain (Azam et al., 1983), hence indirectly sustaining higher order organisms including in-

52 vertebrates and fish. They are also an essential component of the coral holobiont, and disturbing

53 the balance between the corals and their associated microbiota has been implicated in reduced

54 reef health (Dinsdale et al., 2008; Bruce et al., 2012). In addition, the small size and fast repro-

55 duction rate of microorganisms make them very efficient at cycling nutrients, metabolizing for-

56 eign compounds in marine ecosystems and colonizing new ecological niches (Thurber et al.,

57 2009).

58 In the GBR lagoon, river runoff from agricultural areas introduces sediments, excess nutrients

59 from fertilizers (e.g. phosphate and nitrate) and pesticides (herbicides or insecticides) from the

60 land to the inshore waters (Furnas, 2003; Brodie et al., 2012), predominantly during discrete,

61 short-lived flood events during the 5-month summer monsoonal wet season. Land use changes

62 over the past 200 years (increased agriculture, urbanization) have increased the amounts of sedi-

63 ments, nitrogen, phosphorus and herbicides in these floodwaters (Devlin \& Brodie, 2005; Devlin

64 et al., 2012a), with profound impacts on coastal ecosystems (Schaffelke, Mellors \& Duke, 2005;

65 Fabricius, 2005; Brodie \& Mitchell, 2005; De’ath \& Fabricius, 2011; Schaffelke et al., 2013).

66 Particularly high levels of herbicides such as diuron are currently found in the GBR lagoon,

67 which inhibits the photosystem II and damages mangroves, seagrass, corals, and other non-target

68 photosynthetic organisms (Lewis et al., 2009; Shaw et al., 2010). While herbicides can be toxic to some microorganisms (Leboulanger et al., 2008), they can be neutral to others that have dedicated enzymes for their degradation (Aislabie \& Lloyd-Jones, 1995). To date, microbial communities co-existing with the other macroscopic species on the GBR have not been characterized and it is unclear how anthropogenic compounds found in seasonal runoff affect these communi73 ties.

74 In this study, we characterized planktonic microbial communities of seven GBR lagoon sites differentially exposed to inputs from the rivers of the Wet Tropics catchment. Over three years, we determined water chemistry and characterized microbial communities using 16S rRNA gene amplicon sequencing. We hypothesized that microbial communities follow seasonal dynamics and respond to riverine input, potentially buffering reef ecosystems against effects of elevated flood- 
water constituents through nutrient cycling and detoxification.

\section{Materials \& Methods}

\section{Sampling design}

Sampling was performed in the Wet Tropics Region of the GBR (Figure 1), a well-studied coastal area which is regularly exposed to river runoff and flood events (Devlin \& Schaffelke, 2009; Schroeder et al., 2012; Turner et al., 2013). The sites surveyed were located on a transect following a gradient of river exposure, from the highly-exposed Tully River mouth (TT1) to the fringing coral reefs of Dunk Island (TT3) that are seasonally reached by flood plumes, and the TT4 offshore location, rarely exposed to river water. Russel (RI) and Fitzroy islands (FI) were additional reef sites with limited exposure to the waters of the Johnstone and Russel rivers, respectively, and a consistently higher coral health index than Dunk Island (Thompson et al., 2014). All sampling sites were classified based on their proximity to the nearest influencing river mouth: 'plume' for $<20 \mathrm{~km}$ downstream and 'marine' if $>20 \mathrm{~km}$ (Table S1). To characterize the influence of riverine microorganisms on marine communities, a freshwater site located $12 \mathrm{~km}$ upstream of the river mouth was also selected (TR).

The seven sites were surveyed between January 2011 and October 2013 in the dry season (June), just prior to the wet season (October), and at the end of the wet season (March). At each site and sampling date, a single $2 \mathrm{~L}$ seawater sample was taken from a depth of $5 \mathrm{~m}$ (just below surface for the TR site, which was a very shallow river bed), passed through a $0.22 \mu \mathrm{m}$ Sterivex filter, which was stored at $-20^{\circ} \mathrm{C}$ until further processing. All samples were collected under the auspices of the general permit (G12/35236.1) granted by the Great Barrier Reef Marine Park Authority to the Australian Institute of Marine Science.

\section{Environmental conditions}

Water samples collected from 2011 to 2013 were processed according to the long-term GBR Reef Rescue Marine Monitoring Program (Thompson et al., 2013) to assess temperature, salinity, bottom depth and water chemistry: concentrations of suspended solids (SS), particulate organic carbon (POC), particulate phosphorus (PP), particulate nitrogen (PN), dissolved inorganic nitrogen (DIN), silica (Si) and chlorophyll a (CHLA). In addition, diuron concentration was determined by collecting $1 \mathrm{~L}$ of water in pre-washed bottles, and storing the water at $4^{\circ} \mathrm{C}$ until processing by 
108 solid phase extraction liquid chromatography tandem mass spectrometry (SPE-LC-MS/MS) at

109 Queensland Health and Forensic Scientific Services, Coopers Plains, Australia. All these mea-

110 sured environmental parameters were deposited as NCBI BioSamples (accession \# PR-

111 JNA276058). In addition, meteorological parameters were acquired from public resources: Tully

112 River discharge and water temperature (Department of Natural Resources and Mines, http://wa-

113 termonitoring.derm.qld.gov.au/host.htm), and solar exposure and rainfall (Bureau of Meteorol-

114 ogy, http://www.bom.gov.au/climate/data/index.shtml). An average of these meteorological pa-

115 rameters was calculated for the seven days preceding each sampling date.

116 A river exposure index was calculated using a hydrodynamic model (http://www.bom.gov.au/en-

117 vironment/activities/coastal-info.shtml), based primarily on the Sparse Hydrodynamic Ocean

118 Code (SHOC) hydrodynamic model

119 (http://www.emg.cmar.csiro.au/www/en/emg/software/EMS/hydrodynamics.html). SHOC is a

120 general purpose model, applicable on spatial scales ranging from estuaries to regional ocean do-

121 mains (Herzfeld, 2006). We used outputs from the regional application of SHOC to the GBR us-

122 ing a horizontal spatial resolution of about $4 \mathrm{~km}$, with a model grid size of 180×600 with 48 ver-

123 tical layers with $1 \mathrm{~m}$ resolution at the surface. In this context, conservative tracers were used in

124 this study to simulate the transport of unique tracers 'released' from different rivers. In mathemat-

125 ical terms, a conservative substance is represented without terms of sinks or sources of mass in

126 the transport equation. This means that the change in concentration values happens due to physi-

127 cal processes (advection and diffusion). Furthermore, it was stipulated that the tracers used do not

128 affect the hydrodynamics. This technique enables the identification of marine regions influenced

129 by individual catchments, and provides insight into the mixing and retention of river water along

130 various regions in a given domain (Brinkman et al., 2002, 2014; Luick et al., 2007). Model simu-

131 lations of the 3-dimensional distributions of passive tracers were analyzed to produce weekly es-

132 timates of cumulative exposure to tracers above a threshold of $1 \%$ of the source concentration.

133 An exposure index was calculated that integrates the tracer concentrations above this threshold,

134 based on a cumulative measurement of the exposure concentration and duration of exposure re-

135 lated to individual river sources, and expressed as Concentration x Days (conc.d). For every loca-

136 tion in the model domain, the cumulative exposure index was calculated as:

137 Conc.Days $=\sum_{t=0}^{T}$ Conc $_{\text {exceed }} \times t$ where $\quad \operatorname{Conc}_{\text {exceed }}=\left\{\begin{array}{c}\operatorname{Conc}(t)-\text { Conc }_{\text {thresh }}, \text { if Conc }(t)>\text { Conc }_{\text {thresh }} \\ 0, \text { if Conc }(t) \leq \text { Conc }_{\text {thresh }}\end{array}\right.$ 
138 and Conc $_{\text {thresh }}$ is defined as $1 \%$ of the source concentration, $\operatorname{Conc}(t)$ represents the time-varying

139 tracer concentration, and $t$ is the time in days from the beginning of the wet season to the end (01

140 November - 31 March). Cumulative exposure was calculated for each grid point in the model do-

141 main. Using this representation, the exposure index integrates both concentration above a defined

142 threshold and the duration of exposure. For example, an exposure of 20 days at a concentration of

$1431 \%$ above the threshold would produce an index value of 0.2 , which is equivalent to 10 days ex-

144 posure at 2\% above the concentration threshold. This index provides a consistent approach to as-

145 sess relative differences in exposure of inshore GBR waters to inputs from various rivers. For

146 each of the wet seasons simulated by the model, spatial maps of river exposure indices were cal-

147 culated for the target rivers: Herbert, Tully, Murray, Johnstone, Mulgrave and Russel rivers (Wet

148 Tropics catchment), Burdekin and Haughton rivers (Burdekin catchment, affecting the south of

149 the Wet Tropics catchment).

$150 \quad$ 16S rRNA gene amplicon sequencing

151 DNA was extracted from each Sterivex filter using a modified method from Suzuki et al. (2004).

152 In brief, the filters were thawed on ice with Invitrogen's P1 buffer with lysozyme at a final con-

153 centration of $2 \mathrm{mg} / \mathrm{mL}$, and incubated for $30 \mathrm{~min}$ at $37^{\circ} \mathrm{C}$, while rotating at $10 \mathrm{rpm}$. Proteinase $\mathrm{K}$

154 (0.75 mg/mL final concentration) and $10 \%$ sodium dodecyl sulfate ( $1 \%$ final concentration)

155 were added and the sample was incubated, with rotation, at $55^{\circ} \mathrm{C}$ for $2 \mathrm{~h}$. DNA was extracted us-

156 ing phenol:choloroform:isoamyl alcohol (25:24:1; pH 8.0) followed by an overnight ethanol pre-

157 cipitation and purified using a MO BIO PowerClean DNA Clean-Up kit (Carlsbad, CA).

158 Amplicons were generated by PCR-amplifying the V6 to V8 variable regions of the 16S rRNA

159 gene using the pyroLSSU926F and pyroLSSU926F universal primers as described in Dove et al.

160 (2013). The resulting DNA amplicons were sequenced on a Roche-454 GS-FLX instrument at the

161 Australian Centre for Ecogenomics and deposited in the NCBI Short Read Archive (accession \#

162 PRJNA276058).

\section{$163 \quad$ Bioinformatic processing}

164 Amplicon reads were processed using Hitman (https://github.com/fangly/hitman), a bioinformatic

165 workflow based around the UPARSE methodology (Edgar, 2013). In brief, Hitman: 1) joins read

166 pairs with PEAR (Zhang et al., 2014), but keeps the forward read when pairs cannot be joined; 2)

167 truncates the 3 ' end of sequences at the first residue below a threshold quality value $(Q)$ using

168 TRIMMOMATIC (Bolger, Lohse \& Usadel, 2014); 3) trims the 3' end of all sequences to a target 
169 length $(L)$ using TRIMMOMATIC, discarding all smaller sequences, 4) removes sequences ex-

170 ceeding the maximum number of expected errors $(E)$ using USEARCH's fastq_filter (Edgar \&

171 Flyvbjerg, 2015); 5) uses USEARCH's cluster_otus to form operational taxonomic units (OTUs)

172 from high-fidelity sequences (stringent quality processing in steps 2 and 4) that are sorted by de-

173 creasing abundance, occur at least twice in the dataset and meet a minimum percentage of simi-

174 larity $(O)$; 6) discards chimeric OTUs using USEARCH's cluster_otus in a reference-indepen-

175 dent, and using UCHIME (Edgar et al., 2011) based on a reference database $(C)$; 7) assigns regu-

176 lar-fidelity sequences (less stringent quality processing in steps 2 and 4) to each OTU using USE-

177 ARCH's usearch_global (Edgar, 2010); 8) formats the results in BIOM format using Bio-Com-

178 munity's bc_convert_files (Angly, Fields \& Tyson, 2014); 9) gives a taxonomic assignment to

179 each OTU by globally aligning their representative sequences against a database $(T)$ of reference

180 sequences trimmed to the target region (keeping only the best-matching alignment with a mini-

181 mum required identity percentage (I) using USEARCH's usearch_global; 10) removes OTUs be-

182 longing to specific taxa (W) using Bio-Community's bc_manage_samples; 11) rarefies the micro-

183 bial profiles at the given depth $(D)$ with Bio-Community's bc_accumulate assuming an infinite

184 number of bootstrap replicates; and 12) corrects gene-copy number bias using CopyRighter (An-

185 gly et al., 2014).

186 In this study, Hitman was run using the following parameters: $L=250 \mathrm{bp}, Q=7$ (16 for HiFi se-

187 quences), $E=3.0$ expected errors ( 0.5 for HiFi sequences), $O=97 \%$ identity (species-level),

$188 C=$ GOLD database (Bernal, Ear \& Kyrpides, 2001), $T=$ merged Silva (Quast et al., 2012) and

189 Greengenes (McDonald et al., 2012) databases (https://github.com/fangly/merge gg silva),

$190 I=95 \%$ identity (genus-level), $W=$ “Eukaryota* *Chloroplast*” and $D=279$ for Bacteria \& Archaea

191 (100 for Eukaryotes). In addition, rarefaction curves were generated using Bio-Community (An-

192 gly, Fields \& Tyson, 2014).

193 Statistical analysis

194 All statistical analyses were carried out using the R language (R Foundation for Statistical Com-

195 puting, Vienna, Austria). Comparisons of diversity between groups of samples were carried out

196 using the non-parametric, unilateral Mann-Whitney U test (wilcox.test() function). Principal co-

197 ordinates analysis (PCoA) and PERMANOVA were performed using the capscale() and adonis()

198 functions of the vegan package (Dixon, 2003). The indicspecies package (Cáceres \& Legendre,

199 2009) was used to determine indicator species with the multipatt() function. Redundancy analysis

200 (RDA) model selection was based on the AIC (Akaike information criterion) and calculated by 
201 ordistep() in vegan. Pearson correlations between environment variables were computed using

202 rcorr() from the Hmisc package. The functions fa.parallel(), fa(), target.rot() and fa.diagram()

203 from the psych package were used to conduct exploratory factor analysis (EFA), i.e. to identify

204 groups of co-varying variables. EFA was performed on several subsets of the data including dif-

205 ferent environmental parameters and the results were summarized.

\section{Results \& Discussion}

\section{Sampling and environmental context}

208 Seven inshore GBR sites exposed to different levels of river runoff from the Wet Tropics catch-

209 ments were surveyed over three years for water chemistry assessments and determination of mi-

210 crobial community structure. The classification of these sites as plume or marine sites was based

211 on their distance to the nearest influencing river mouth (Table S1) and matched well with their

212 river exposure index as calculated by oceanographic modeling (Figure 1); sites <20 km from a

213 river mouth were more highly exposed to riverine water ( $>20$ conc.d) than sites $>20 \mathrm{~km}$ away

214 (<15 conc.d).

215 The weather in the Tully catchment from 2010 to 2013 followed the expected seasonal dynamics,

216 dry and cool conditions between the months of May and October, hot and humid with most of the

217 annual rainfall from November to April (Figure 2). However, the 2010-11 wet season was

218 marked by extreme weather (Table S2) and the landfall of category 5 tropical cyclone Yasi (3

219 February 2011), that significantly affected coral reefs (Perry et al., 2014). Annual river discharges

220 reached a record high (Schaffelke et al., 2011), causing elevated exposure to nutrients, PSII herbi-

221 cides and sediments across most inshore GBR regions (Devlin et al., 2012b; Kennedy et al.,

222 2012; Perry et al., 2014). The following wet season (2011-12) represented a return to typical

223 weather conditions, with river discharge close to the long-term median (Schaffelke et al., 2012a;

224 Wallace et al., 2014). However, coral reef recovery was delayed until 2014, when the coral health

225 index reached pre-2011 levels again (Thompson et al., 2014).

$226 \quad$ Microbial diversity

227 The archaeal and bacterial microbial profiles obtained by Roche-454 sequencing of 16S rRNA

228 gene amplicons were rarefied (279 counts per sample) to allow comparison of microbial profiles

229 (Figure S1). A ten times higher sequencing effort would have been needed to sample nearly all 
230 the OTUs present in these aquatic samples (richness; Figure S1 A). Nevertheless, the chosen rar-

231 efaction depth recovered the vast majority of archaeal and bacterial diversity (Shannon-Wiener

232 index; Figure S1 B). The microbial diversity of the rarefied profiles was calculated, with a me-

233 dian richness of $\sim 65$ OTUs in the river, and $\sim 90-100$ at the marine and plume sites (Figure $3 \mathrm{~A}$ ).

234 At plume sites, richness (Figure $3 \mathrm{~A}$ ) and evenness (Figure $3 \mathrm{~B}$ ) were higher in the dry season

235 than in the wet season, which corresponded to a larger overall diversity (Shannon-Wiener index)

236 in the dry season (Figure $3 \mathrm{C}$ ) (Mann-Whitney U test; $\mathrm{p}<0.05$ ).

\section{Establishing a microbial monitoring baseline for inshore GBR}

238 Taxonomic assignments and gene copy number correction were conducted to produce accurate

239 estimates of microbial relative abundance (Angly et al., 2014) (Figure S2) that yield an under-

240 standing of the prevalence of microbial taxa in the GBR lagoon waters. At a coarse taxonomic

241 level, the bacterial orders Sphingobacteriales, Burkholderiales, and Xanthomonadales dominated

242 the TR river site (Figure 4), while the archaeal order E2 and bacterial orders Rickettsiales and

243 Synechococcales were prevalent at the plume and marine sites (Figure 4). On average, Rick-

244 ettsiales and E2 had higher relative abundance at the marine sites (29.6 and $17.7 \%$ respectively)

245 compared to the plume sites (20.4 and 10.4\% respectively). This distribution was not constant

246 over time, and notably, the plume sites were characterized by a large fraction of Burkholderiales

247 in the January - March 2011 period, i.e. the extreme wet season 2010-11. Flavobacteriales were

248 found in all sites, riverine, plume and marine. Burkholderiales are Betaproteobacteria commonly

249 found in rivers (Cottrell et al., 2005; Ghai et al., 2011; Liu et al., 2012). Sphingobacteriales have

250 been reported at riverine locations affected by waste water treatment effluent (Drury, Rosi-Mar-

251 shall \& Kelly, 2013), where they may degrade complex compounds such as herbicides and antibi-

252 otics (Kämpfer, 2011). Synechococcales such as those found in the plume and marine sites in-

253 clude the Synechococcus and Prochlorococcus genera, which represent the main photosynthetic

254 bacteria in oceanic waters (Partensky, Blanchot \& Vaulot, 1999; Partensky, Hess \& Vaulot, 1999),

255 and the small heterotrophic Rickettsiales are also commonly reported in the ocean (Morris et al.,

256 2002; Carlson et al., 2008). More specifically, both orders were previously identified in coral reef

257 waters (Kelly et al., 2012; Lu et al., 2015). However, Thermoplasmata E2 Archaea have only oc-

258 casionally been reported in temperate surface seawater (Massana et al., 1997; Pernthaler et al.,

259 2002). These Archaea are motile photo-heterotrophic cells focused on the degradation of protein

260 and lipids (Iverson et al., 2012) and are found in coral mucus, suggesting a potential role in main-

261 taining coral health (Kellogg, 2004). 
262 Genomic methods such as 16S rRNA gene amplicon sequencing are effective for marine monitor263 ing (Bourlat et al., 2013). The present taxonomic characterization of the microbial communities

264 in inshore GBR waters represents a baseline against which future microbiological studies can be 265 compared. This baseline may prove valuable for assessing future change in this reef ecosystem, 266 be it further degradation or recovery.

\section{Geographical and temporal distribution of OTUs}

268 Non-constrained ordination (PCoA) was applied to get a precise account of the dynamics and dis269 tribution of specific microbial taxa in inshore GBR. At the finer operational taxonomic unit

270 (OTU) level (Figure 5 A), significant spatial (distance to river mouth and site type; PER-

271 MANOVA, $\mathrm{p}<0.05$ ) and temporal effects (wet or dry; PERMANOVA, $\mathrm{p}<0.05$ ) were confirmed.

272 Site type (riverine, plume or marine) had the strongest effect (27.8\% explained variance along

273 PC1, Figure 5 A), followed by seasons (wet or dry) (10.0\% explained variance along PC2, Figure $2745 \mathrm{~A})$.

275 Marine and plume samples were characterized by indicator OTUs, i.e. OTUs characteristic of the 276 marine and plume areas (indicator species analysis; $\mathrm{p}<0.05$ ). These indicator OTUs belonged to 277 the Rickettsiales (e.g. Pelagibacteraceae), Synechococcales (e.g. Prochlorococcus), Acidimicro278 biales (e.g. OCS155), and the Archaeal order E2 (e.g. Marine Group II) (Figure 5 A), which is 279 largely consistent with the trends observed at the order level (Figure 4). The main difference be280 tween the OTU- and order-level analyses (Figure 5 and Figure 4 respectively) was the detection of OCS155, an OTU indicator of marine and plume sites (Figure 5 A). OCS155 belongs to the

282 Acidimicrobiales, a group of likely planktonic, free-living microorganisms with a photo-het283 erotrophic lifestyle (Mizuno, Rodriguez-Valera \& Ghai, 2015) found in all tropical and temperate 284 photic areas (Ghai et al., 2013).

285 Indicator OTUs for the river samples were also identified (indicator species analysis; $\mathrm{p}<0.05$ ), in286 cluding members of the orders Burkholderiales (family Comamonadaceae, e.g. Limnohabitans, 287 Acidovorax and Rhodoferax; family Oxalobacteraceae), and Sphingobacteriales (family Flexibac288 teraceae, e.g. Arcicella; family Chitinophagaceae) (Figure 5 A). These results are congruent with 289 those at the order level (Figure 4). The presence of riverine OTUs belonging to the order

290 Burkholderiales and Sphingobacteriales at some plume sites surveyed in the wet months (Figure

291 4, Figure 5 A), when river discharge is high, is a sign that these sites are affected by riverine wa292 ter effluent. 
293 When repeating the PCoA with the marine samples only, i.e. restricting the analysis to samples

294 unaffected by river output, a clear partition between dry and wet seasons (Figure 5 B) was seen

295 (PERMANOVA, $\mathrm{p}<0.05$ ). All samples clustered in one of two season-specific groups arranged

296 along PC1, except for one sample collected at TT4 in December 2011. Several indicator OTUs

297 were identified (indicator species analysis; $\mathrm{p}<0.05$ )(Table S3), e.g. Pelagibacteraceae (3 OTUs),

298 Pirellulaceae (2 OTUs) and Marine group II (2 OTUs), which were specific of the dry season.

299 Generally though, Marine group II OTUs seemed to be more abundant in the wet season (Figure

$3005 \mathrm{~A}$ and B). Previous studies have shown seasonality in near-shore microbial communities

301 (Treusch et al., 2009; Gilbert et al., 2009, 2012). In particular, Pelagibacter is known to exhibit

302 seasonality (Alonso-Sáez et al., 2007; Carlson et al., 2008; Eiler et al., 2009; Fortunato et al.,

303 2013). Overall, the microbial communities of the GBR lagoon seem to respond to seasonal influ-

304 ence, although it is not as pronounced as the influence of geographical location, an observation

305 that was also made in a previous investigation of river to ocean gradient (Fortunato et al., 2012).

306 In addition to a seasonal effects, GBR lagoon samples were susceptible to short term effects of

307 potentially high magnitude. Rapid community changes were evident when looking at the Tully

308 transect samples (TT1-4) collected in the wake of Cyclone Yasi (03 Feb 2011) (Figure S3). The

309 influence of Tully river input was marked, with elevated levels of Sphingobacteriales and

310 Burkholderiales recorded between 13 and 17 February. While these changes were especially pro-

311 nounced at the Tully River mouth, even the offshore site TT4 experienced analogous changes in

312 this period. Especially large changes in community structure were observed between consecutive

313 days, on February 12-13 (Figure 2). These findings add to previous investigations of soil and gut

314 microbiota, which have shown that community composition can change within a few days

315 (Schmidt et al., 2007; Michelland et al., 2011; David et al., 2014). While baselines may be estab-

316 lished using e.g. monthly sampling, it is clear that future research should adopt an intensive daily

317 sampling regimen to better characterize such transient changes in estuarine and marine microbial

318 communities.

319 Environmental drivers of coastal microbial dynamics

320 A range of measurements describing the environmental context of the microbial samples were

321 collected in this study, including temperature, salinity, bottom depth and water chemistry vari-

322 ables (concentrations of suspended solids, silica, chlorophyll $a$, the herbicide diuron, dissolved

323 and particulate form of carbon, nitrogen and phosphorus), and complemented with weather con-

324 dition data (Tully River discharge, local rainfall and solar exposure). Many of these environmen- 
325 tal parameters were highly correlated (Pearson test; $48.6 \%$ of the pairs with $\mathrm{r}>0.3$ ), requiring the 326 need for EFA to extract groups of uncorrelated parameters. Following this procedure (Figure S4), 327 four independent factors were identified. Factor MR1 included local rainfall and Tully River dis328 charge. Factor MR2 included chlorophyll $a$, suspended solids and other particulates (POC, PN, 329 PP). Factor MR3 included DIN and salinity and can be interpreted as mixing with freshwater.

330 Factor MR4 combined water temperatures and solar exposure. Although larger discharge (factor 331 MR1) can lead to increased suspended solids (factor MR2) and salinity decrease (factor MR3), 332 factor MR1, MR2 and MR3 were not directly correlated because salinity and the amount of sus333 pended solids depend not only on site location (proximity to the river mouth) but also on the ac334 tion of wind and waves, which homogenize the water column and resuspend sediments (Lar335 combe et al., 1995; Orpin \& Ridd, 2012; Fabricius et al., 2014). A water quality index based on 336 comparison to water quality guidelines (GBRMPA, 2010) and ranging from -1 for poor quality to $337+1$ for very good quality was previously introduced (Thompson et al., 2013). This index aggre338 gates scores given to four indicator concentrations (suspended solids, chlorophyll $a$, particulate nitrogen, particulate phosphorus), which are all part of the suspended material factor (factor MR2) identified by EFA in the present study. Diuron has a strong association with sediments

341 (Stork, Bennett \& Bell, 2008; Balakrishnan, Takeda \& Sakugawa, 2012; Xu et al., 2013) and is 342 also included in this factor. Overall, this suggests that factor MR2 can be interpreted as the qual343 ity of the water.

344 Constrained ordinations (RDA) were carried out to study the relative importance of the four inde345 pendent factors (MR1-4) on microbial community structure. A single environmental parameter 346 was chosen to represent each factor prior to conducting RDA with model selection: rainfall for 347 factor MR1, water quality index for MR2, salinity for MR3, and water temperature for MR4 (Fig348 ure 6). These four environmental parameters were significantly associated with microbial com349 munity composition (PERMANOVA, $\mathrm{p}<0.05$ ). Microbial community structure was affected by 350 temperature (Figure $6 \mathrm{~A}$ ), consistent with previous findings in the Western English Channel 351 (Gilbert et al., 2009), which could explain the seasonality identified in marine sites. Further, sea352 sonality can be attributed to the higher rainfall typical of the wet season (Figure 6 A). However, 353 large changes could be attributed to decreases in water quality index and salinity, especially for 354 plume sites (Figure 6 A), with negative consequences for corals (Fabricius et al., 2014). These 355 changes can be interpreted as the effect of riverine floodwater, which was especially pronounced 356 for sites located near the Tully river mouth, and helps explain the geographical pattern seen in mi- 
357 crobial communities. The effects of salinity and water quality index were mostly collinear in Fig-

358 ure $6 \mathrm{~A}$, despite the fact that they represent two separate factors (MR2 and MR3). Repeating the

359 RDA analysis with the influence of salinity removed (conditioning term, Figure 6 B), water qual-

360 ity index was still identified as a significant driver of microbial communities (PERMANOVA,

$361 \mathrm{p}<0.05)$. This suggests that, as a whole, nutrient, organic compounds and herbicides such as di-

362 uron brought by riverine water into the ocean have an effect on microbial communities.

363 RDA analysis was also conducted to identify the factors driving the large, transient changes de-

364 tected by microbial profiling at the plume sites on 12-13 February 2011 (Figure S5). Being only

365 nine days after the landfall of tropical cyclone Yasi, this period was characterized by extreme

366 weather, e.g. high river discharge (12 Feb: 37.1 ML/d; 13 Feb: 36.2 ML/d; 7-13 Feb mean: 27.5

$367 \mathrm{ML} / \mathrm{d}$ ). While river discharge was similar on the two days, the February 13 microbial communi-

368 ties were characterized by elevated levels of suspended solids and lower salinity (PERMANOVA, $369 \mathrm{p}<0.05$ ), suggesting that other environmental factors may contribute to microbial community

370 structure. We speculate that larger wind or waves were present on February 13, which would

371 have decreased the vertical stratification of the water column, resulting in lower salinity and

372 higher concentration of suspended solids. This example illustrates that salinity and suspended

373 solids at inshore locations may be a function of both river flow and wind (Schaffelke et al.,

374 2012b; Fabricius et al., 2014). The 12 February was also marked by an increase in the eukaryotic

375 to prokaryotic reads ratio (EPR) (Figure S6), with a maximum EPR of 1.45 reached on February

37613 at TT1. The most abundant eukaryal taxon in this sample was assigned to the hydrozoan genus

377 Merona, that includes very small organisms that can spawn eggs (Schuchert, 2004). These data

378 could be interpreted as the potential spawning of hydrozoan or the displacement from their usual

379 habitat (e.g. the benthic zone) and they illustrate that extreme weather may dramatically change

380 environmental conditions, thereby affecting all microbial kingdoms (Archaea, Bacteria and Eu-

381 karyota).

\section{Conclusions}

383 This study is a baseline description of microbial communities in the inshore GBR lagoon. Marine

384 Group II Archaea, Pelagibacteraceae and Rickettsiales were prevalent in all the seawater samples.

385 A seasonal effect of temperature and rainfall on the microbial communities was apparent in the

386 three year sampling period. However spatial effects were more pronounced, with sites located

387 close to the Tully river mouth including many river-specific taxa, particularly during the wet sea-

388 son. Seasonal storms like those that occurred in the wet season 2010-11 caused elevated sus- 
389 pended solids and decreased salinity at plume sites, which translated into large, transient changes

390 in microbial community structure. Water quality played a role in driving microbial community

391 structure in the GBR lagoon, but the complex interconnections between environmental parame-

392 ters mean that future research such as experimental manipulations will be needed to precisely elu-

393 cidate how each individual anthropogenic compound shapes microbial community composition

394 and affects coral reefs.

395

396

397

398

399

\section{References}

Aislabie J., Lloyd-Jones G. 1995. A review of bacterial-degradation of pesticides. Soil Res. 33:925-942.

Alonso-Sáez L., Balagué V., Sà EL., Sánchez O., González JM., Pinhassi J., Massana R., Pernthaler J., Pedrós-Alió C., Gasol JM. 2007. Seasonality in bacterial diversity in northwest Mediterranean coastal waters: assessment through clone libraries, fingerprinting and FISH. FEMS Microbiology Ecology 60:98-112.

Angly FE., Dennis PG., Skarshewski A., Vanwonterghem I., Hugenholtz P., Tyson GW. 2014. CopyRighter: a rapid tool for improving the accuracy of microbial community profiles through lineage-specific gene copy number correction. Microbiome 2:11.

Angly FE., Fields CJ., Tyson GW. 2014. The Bio-Community Perl toolkit for microbial ecology. Bioinformatics:btu130.

Azam F., Fenchel T., Field JG., Gray JS., Meyer-Reil LA., Thingstad F. 1983. The ecological role of water-column microbes in the sea. Marine Ecology Progress Series 10:257-263.

Balakrishnan S., Takeda K., Sakugawa H. 2012. Occurrence of Diuron and Irgarol in seawater, 
sediments and planktons of Seto Inland Sea, Japan. Geochemical Journal 46:169-177.

Bernal A., Ear U., Kyrpides N. 2001. Genomes OnLine Database (GOLD): a monitor of genome projects world-wide. Nucleic Acids Research 29:126-127.

Bolger AM., Lohse M., Usadel B. 2014. Trimmomatic: a flexible trimmer for Illumina sequence data. Bioinformatics:btu170.

Bourlat SJ., Borja A., Gilbert J., Taylor MI., Davies N., Weisberg SB., Griffith JF., Lettieri T., Field D., Benzie J., Glöckner FO., Rodríguez-Ezpeleta N., Faith DP., Bean TP., Obst M. 2013. Genomics in marine monitoring: New opportunities for assessing marine health status. Marine Pollution Bulletin 74:19-31.

Brinkman R., Wolanski E., Deleersnijder E., McAllister F., Skirving W. 2002. Oceanic inflow from the Coral Sea into the Great Barrier Reef. Estuarine, Coastal and Shelf Science 54:655-668.

Brinkman R., Tonin H., Furnas M., Schaffelke B., Fabricius K. 2014. Targeted analysis of the linkages between river runoff and risks for crown-of-thorns starfish outbreaks in the Northern GBR. Townsville, QLD, Australia: Australian Institute of Marine Science.

Brodie JE., Kroon FJ., Schaffelke B., Wolanski EC., Lewis SE., Devlin MJ., Bohnet IC., Bainbridge ZT., Waterhouse J., Davis AM. 2012. Terrestrial pollutant runoff to the Great Barrier Reef: An update of issues, priorities and management responses. Marine Pollution Bulletin 65:81-100.

Brodie J., Mitchell A. 2005. Nutrients in Australian tropical rivers: changes with agricultural development and implications for receiving environments. Marine \& Freshwater Research 56:279-302.

Bruce T., Meirelles PM., Garcia G., Paranhos R., Rezende CE., de Moura RL., Filho R-F., Coni EOC., Vasconcelos AT., Amado Filho G., Hatay M., Schmieder R., Edwards R., Dinsdale E., Thompson FL. 2012. Abrolhos bank reef health evaluated by means of water quality, microbial diversity, benthic cover, and fish biomass data. PLoS ONE 7:e36687.

Cáceres MD., Legendre P. 2009. Associations between species and groups of sites: indices and statistical inference. Ecology 90:3566-3574. 
Carlson CA., Morris R., Parsons R., Treusch AH., Giovannoni SJ., Vergin K. 2008. Seasonal dynamics of SAR11 populations in the euphotic and mesopelagic zones of the northwestern Sargasso Sea. The ISME Journal 3:283-295.

Cottrell MT., Waidner LA., Yu L., Kirchman DL. 2005. Bacterial diversity of metagenomic and PCR libraries from the Delaware River. Environmental Microbiology 7:1883-1895.

David LA., Maurice CF., Carmody RN., Gootenberg DB., Button JE., Wolfe BE., Ling AV., Devlin AS., Varma Y., Fischbach MA., Biddinger SB., Dutton RJ., Turnbaugh PJ. 2014. Diet rapidly and reproducibly alters the human gut microbiome. Nature 505:559-563.

De’ath G., Fabricius KE., Sweatman H., Puotinen M. 2012. The 27-year decline of coral cover on the Great Barrier Reef and its causes. Proceedings of the National Academy of Sciences.

De'ath G., Fabricius K. 2011. Evidence that water quality is an important driver of reef biota is not refuted: response to Ridd et al. Ecological Applications 21:3335-3336.

Devlin MJ., McKinna LW., Álvarez-Romero JG., Petus C., Abott B., Harkness P., Brodie J. 2012a. Mapping the pollutants in surface riverine flood plume waters in the Great Barrier Reef, Australia. Marine Pollution Bulletin 65:224-235.

Devlin M., Wenger A., Da Silva E., Alvarez Romero JG., Waterhouse J., McKenzie L. $2012 b$. Extreme weather conditions in the Great Barrier Reef: drivers of change? In: Yellowlees D, Hughes TP eds. Townsville, QLD, Australia: James Cook University, 1-5.

Devlin MJ., Brodie J. 2005. Terrestrial discharge into the Great Barrier Reef lagoon: nutrient behavior in coastal waters. Marine Pollution Bulletin 51:9-22.

Devlin M., Schaffelke B. 2009. Spatial extent of riverine flood plumes and exposure of marine ecosystems in the Tully coastal region, Great Barrier Reef. Marine and Freshwater Research 60:1109-1122.

Dinsdale EA., Pantos O., Smriga S., Edwards RA., Angly F., Wegley L., Hatay M., Hall D., Brown E., Haynes M., Krause L., Sala E., Sandin SA., Thurber RV., Willis BL., Azam F., Knowlton N., Rohwer F. 2008. Microbial ecology of four coral atolls in the northern Line Islands. PLOS ONE 3:e1584. 
Dixon P. 2003. VEGAN, a package of R functions for community ecology. Journal of Vegetation Science 14:927-930.

Dove SG., Kline DI., Pantos O., Angly FE., Tyson GW., Hoegh-Guldberg O. 2013. Future reef decalcification under a business-as-usual CO2 emission scenario. Proceedings of the National Academy of Sciences:201302701.

Drury B., Rosi-Marshall E., Kelly JJ. 2013. Wastewater treatment effluent reduces the abundance and diversity of benthic bacterial communities in urban and suburban rivers. Applied and Environmental Microbiology 79:1897-1905.

Edgar RC. 2010. Search and clustering orders of magnitude faster than BLAST. Bioinformatics 26:2460-2461.

Edgar RC., Haas BJ., Clemente JC., Quince C., Knight R. 2011. UCHIME improves sensitivity and speed of chimera detection. Bioinformatics 27:2194-2200.

Edgar RC. 2013. UPARSE: highly accurate OTU sequences from microbial amplicon reads. Nature Methods 10:996-998.

Edgar RC., Flyvbjerg H. 2015. Error filtering, pair assembly and error correction for nextgeneration sequencing reads. Bioinformatics:btv401.

Eiler A., Hayakawa DH., Church MJ., Karl DM., Rappé MS. 2009. Dynamics of the SAR11 bacterioplankton lineage in relation to environmental conditions in the oligotrophic North Pacific subtropical gyre. Environmental Microbiology 11:2291-2300.

Fabricius KE. 2005. Effects of terrestrial runoff on the ecology of corals and coral reefs: review and synthesis. Marine Pollution Bulletin 50:125-146.

Fabricius KE., Logan M., Weeks S., Brodie J. 2014. The effects of river run-off on water clarity across the central Great Barrier Reef. Marine Pollution Bulletin 84:191-200.

Fortunato CS., Herfort L., Zuber P., Baptista AM., Crump BC. 2012. Spatial variability overwhelms seasonal patterns in bacterioplankton communities across a river to ocean gradient. The ISME Journal 6:554-563.

Fortunato CS., Eiler A., Herfort L., Needoba JA., Peterson TD., Crump BC. 2013. Determining indicator taxa across spatial and seasonal gradients in the Columbia River coastal margin. 
The ISME Journal 7:1899-1911.

Furnas MJ. 2003. Catchments and corals: terrestrial runoff to the Great Barrier Reef. Australian Institute of Marine Science.

GBRMPA 2010. Water quality guidelines for the Great Barrier Reef Marine Park. Revised edition 2010. Townsville: Great Barrier Reef Marine Park Authority.

Ghai R., Rodriguez-Valera F., McMahon KD., Toyama D., Rinke R., Cristina Souza de Oliveira T., Wagner Garcia J., Pellon de Miranda F., Henrique-Silva F. 2011. Metagenomics of the water column in the pristine upper course of the Amazon River. PLoS ONE 6:e23785.

Ghai R., Mizuno CM., Picazo A., Camacho A., Rodriguez-Valera F. 2013. Metagenomics uncovers a new group of low GC and ultra-small marine Actinobacteria. Scientific Reports 3.

Gilbert JA., Field D., Swift P., Newbold L., Oliver A., Smyth T., Somerfield PJ., Huse S., Joint I. 2009. The seasonal structure of microbial communities in the Western English Channel. Environmental Microbiology 11:3132-3139.

Gilbert JA., Steele JA., Caporaso JG., Steinbrück L., Reeder J., Temperton B., Huse S., McHardy AC., Knight R., Joint I., Somerfield P., Fuhrman JA., Field D. 2012. Defining seasonal marine microbial community dynamics. The ISME Journal 6:298-308.

Herzfeld M. 2006. An alternative coordinate system for solving finite difference ocean models. Ocean Modelling 14:174-196.

Iverson V., Morris RM., Frazar CD., Berthiaume CT., Morales RL., Armbrust EV. 2012. Untangling genomes from metagenomes: revealing an uncultured class of marine Euryarchaeota. Science 335:587-590.

Kämpfer P. 2011. order i. Sphingobacteriales ord. nov. Bergey’s Manual of Systematic Bacteriology: Volume 4: The Bacteroidetes, Spirochaetes, Tenericutes (Mollicutes), Acidobacteria, Fibrobacteres, Fusobacteria, Dictyoglomi, Gemmatimonadetes, Lentisphaerae, Verrucomicrobia, Chlamydiae, and Planctomycetes 4:330.

Kellogg CA. 2004. Tropical archaea: diversity associated with the surface microlayer of corals. Marine Ecology Progress Series 273:81-88. 
Kelly LW., Barott KL., Dinsdale E., Friedlander AM., Nosrat B., Obura D., Sala E., Sandin SA., Smith JE., Vermeij MJA., Williams GJ., Willner D., Rohwer F. 2012. Black reefs: ironinduced phase shifts on coral reefs. The ISME Journal 6:638-649.

Kennedy K., Devlin M., Bentley C., Lee-Chue K., Paxman C., Carter S., Lewis SE., Brodie J., Guy E., Vardy S., Martin KC., Jones A., Packett R., Mueller JF. 2012. The influence of a season of extreme wet weather events on exposure of the World Heritage Area Great Barrier Reef to pesticides. Marine Pollution Bulletin 64:1495-1507.

Larcombe P., Ridd PV., Prytz A., Wilson B. 1995. Factors controlling suspended sediment on inner-shelf coral reefs, Townsville, Australia. Coral Reefs 14:163-171.

Leboulanger C., Bouvy M., Pagano M., Dufour R-A., Got P., Cecchi P. 2008. Responses of planktonic microorganisms from tropical reservoirs to paraquat and deltamethrin exposure. Archives of Environmental Contamination and Toxicology 56:39-51.

Lewis SE., Brodie JE., Bainbridge ZT., Rohde KW., Davis AM., Masters BL., Maughan M., Devlin MJ., Mueller JF., Schaffelke B. 2009. Herbicides: A new threat to the Great Barrier Reef. Environmental Pollution 157:2470-2484.

Liu Z., Huang S., Sun G., Xu Z., Xu M. 2012. Phylogenetic diversity, composition and distribution of bacterioplankton community in the Dongjiang River, China. FEMS Microbiology Ecology 80:30-44.

Lu X., Sun S., Zhang Y-Q., Hollibaugh JT., Mou X. 2015. Temporal and vertical distributions of bacterioplankton at the Gray’s Reef national marine sanctuary. Applied and Environmental Microbiology 81:910-917.

Luick JL., Mason L., Hardy T., Furnas MJ. 2007. Circulation in the Great Barrier Reef Lagoon using numerical tracers and in situ data. Continental Shelf Research 27:757-778.

Massana R., Murray AE., Preston CM., DeLong EF. 1997. Vertical distribution and phylogenetic characterization of marine planktonic Archaea in the Santa Barbara Channel. Applied and Environmental Microbiology 63:50-56.

McDonald D., Price MN., Goodrich J., Nawrocki EP., DeSantis TZ., Probst A., Andersen GL., Knight R., Hugenholtz P. 2012. An improved Greengenes taxonomy with explicit ranks 
for ecological and evolutionary analyses of bacteria and archaea. The ISME Journal 6:610-618.

Michelland RJ., Combes S., Monteils V., Cauquil L., Gidenne T., Fortun-Lamothe L. 2011. Rapid adaptation of the bacterial community in the growing rabbit caecum after a change in dietary fibre supply. Animal: An International Journal of Animal Bioscience 5:17611768.

Mizuno CM., Rodriguez-Valera F., Ghai R. 2015. Genomes of planktonic Acidimicrobiales: widening horizons for marine actinobacteria by metagenomics. mBio 6:e02083-14.

Morris RM., Rappé MS., Connon SA., Vergin KL., Siebold WA., Carlson CA., Giovannoni SJ. 2002. SAR11 clade dominates ocean surface bacterioplankton communities. Nature 420:806-810.

Orpin AR., Ridd PV. 2012. Exposure of inshore corals to suspended sediments due to waveresuspension and river plumes in the central Great Barrier Reef: A reappraisal. Continental Shelf Research 47:55-67.

Pandolfi JM., Bradbury RH., Sala E., Hughes TP., Bjorndal KA., Cooke RG., McArdle D., McClenachan L., Newman MJH., Paredes G., Warner RR., Jackson JBC. 2003. Global trajectories of the long-term decline of coral reef ecosystems. Science 301:955-958.

Partensky F., Blanchot J., Vaulot D. 1999. Differential distribution and ecology of Prochlorococcus and Synechococcus in oceanic waters : a review. Bulletin de l'Institut océanographique:457-475.

Partensky F., Hess WR., Vaulot D. 1999. Prochlorococcus, a marine photosynthetic prokaryote of global significance. Microbiology and Molecular Biology Reviews 63:106-127.

Pernthaler A., Preston CM., Pernthaler J., DeLong EF., Amann R. 2002. Comparison of Fluorescently Labeled Oligonucleotide and Polynucleotide Probes for the Detection of Pelagic Marine Bacteria and Archaea. Applied and Environmental Microbiology 68:661667.

Perry CT., Smithers SG., Kench PS., Pears B. 2014. Impacts of Cyclone Yasi on nearshore, terrigenous sediment-dominated reefs of the central Great Barrier Reef, Australia. 
Geomorphology 222:92-105.

Quast C., Pruesse E., Yilmaz P., Gerken J., Schweer T., Yarza P., Peplies J., Glockner FO. 2012. The SILVA ribosomal RNA gene database project: improved data processing and webbased tools. Nucleic Acids Research 41:D590-D596.

R Foundation for Statistical Computing, Vienna, Austria. R: A language and environment for statistical computing.

Schaffelke B., Carleton J., Doyle J., Furnas M., Gunn K., Skuza M., Wright M., Zagorskis I. 2011. Reef Rescue Marine Monitoring Program. Final report of AIMS activities - Inshore water quality monitoring 2010/2011. Townsville: Australian Institute of Marine Science.

Schaffelke B., Carleton J., Skuza M., Zagorskis I., Furnas MJ. 2012a. Water quality in the inshore Great Barrier Reef lagoon: Implications for long-term monitoring and management. Marine Pollution Bulletin 65:249-260.

Schaffelke B., Carleton J., Costello P., Davidson J., Doyle J., Furnas M., Gunn K., Skuza M., Wright M., Zagorskis I. 2012b. Reef Rescue Marine Monitoring Program. Final report of AIMS activities 2011/12: Inshore water quality monitoring. Townsville: Australian Institute of Marine Science.

Schaffelke B., Anthony K., Blake J., Brodie J., Collier C., Devlin M., Fabricius K., Martin K., McKenzie L., Negri A., Ronan M., Thompson A., Warne M. 2013. Supporting evidence to Scientific consensus statement: Land use impacts on Great Barrier Reef water quality and ecosystem condition. Brisbane: Reef Water Quality Protection Plan Secretariat.

Schaffelke B., Mellors J., Duke NC. 2005. Water quality in the Great Barrier Reef region: responses of mangrove, seagrass and macroalgal communities. Marine Pollution Bulletin 51:279-296.

Schmidt SK., Costello EK., Nemergut DR., Cleveland CC., Reed SC., Weintraub MN., Meyer AF., Martin AM. 2007. Biogeochemical consequences of rapid microbial turnover and seasonal succession in soil. Ecology 88:1379-1385.

Schroeder T., Devlin MJ., Brando VE., Dekker AG., Brodie JE., Clementson LA., McKinna L. 2012. Inter-annual variability of wet season freshwater plume extent into the Great Barrier 
Reef lagoon based on satellite coastal ocean colour observations. Marine Pollution Bulletin 65:210-223.

Schuchert P. 2004. Revision of the European athecate hydroids and their medusae (Hydrozoa, Cnidaria): Families Oceanidae and Pachycordylidae. Revue Suisse de Zoologie 111:315369.

Shaw M., Furnas MJ., Fabricius K., Haynes D., Carter S., Eaglesham G., Mueller JF. 2010. Monitoring pesticides in the Great Barrier Reef. Marine Pollution Bulletin 60:113-122.

Stork PR., Bennett FR., Bell MJ. 2008. The environmental fate of diuron under a conventional production regime in a sugarcane farm during the plant cane phase. Pest Management Science 64:954-963.

Suzuki M., Preston C., Béjà O., de la Torre J., Steward G., DeLong E. 2004. Phylogenetic screening of ribosomal RNA gene-containing clones in bacterial artificial chromosome (BAC) libraries from different depths in Monterey Bay. Microbial Ecology 48:473-488.

Thompson A., Schaffelke B., Logan M., Costello P., Davidson J., Doyle J., Furnas M., Gunn K., Liddy M., Skuza M., Uthicke S., Wright M., Zagorskis I. 2013. Reef Rescue Marine Monitoring Program. Annual report of AIMS activities 2012 to 2013 - Inshore water quality and coral reef monitoring. Townsville: Australian Institute of Marine Science.

Thompson A., Lønborg C., Costello P., Davidson J., Logan M., Furnas M., Gunn K., Liddy M., Skuza M., Uthicke S., Wright M., Zagorskis I. 2014. Marine Monitoring Program. Annual Report of AIMS Activities 2013 to 2014- Inshore water quality and coral reef monitoring. Townsville: Australian Institute of Marine Science.

Thurber RV., Willner-Hall D., Rodriguez-Mueller B., Desnues C., Edwards RA., Angly F., Dinsdale E., Kelly L., Rohwer F. 2009. Metagenomic analysis of stressed coral holobionts. Environmental Microbiology 11:2148-2163.

Treusch AH., Vergin KL., Finlay LA., Donatz MG., Burton RM., Carlson CA., Giovannoni SJ. 2009. Seasonality and vertical structure of microbial communities in an ocean gyre. The ISME Journal 3:1148-1163.

Turner R., Huggins R., Wallace R., Smith R., Warne MSJ. 2013. Great Barrier Reef catchment 
loads monitoring program report 2010-2011. Brisbane: Department of Science, Information Technology, Innovation and the Arts.

Wallace R., Huggins R., Smith R., Turner R., Vardy S., Warne MSJ. 2014. Total suspended solids, nutrient and pesticide loads (2011-2012) for rivers that discharge to the Great Barrier Reef - Great Barrier Reef Catchment Loads Monitoring Program 2011-2012. Brisbane: Department of Science, Information Technology, Innovation and the Arts.

Xu H., Lu A., Yu H., Sun J., Shen M. 2013. Distribution of diuron in coastal seawater and sediments from west sea area of Zhoushan island. Open Journal of Marine Science 03:140-147.

Zhang J., Kobert K., Flouri T., Stamatakis A. 2014. PEAR: a fast and accurate Illumina PairedEnd reAd mergeR. Bioinformatics 30:614-620. 


\section{1}

Overview of sampling area in the GBR lagoon

Figure 1: Overview of sampling area in the GBR lagoon. The river exposure index is shown for the Wet Tropics river catchments in the 2010-11 wet season, with a color bar indicating clustered cumulative exposure (concentration $x$ days) above $1 \%$ of the incoming concentration (capped at 20 conc.d). The direction of the residual coastal current is indicated as a black vector. The location of the sites surveyed for microbial composition in 2011-13 is shown as colored paddles. The sites were classified as marine, plume or riverine, according to their respective distance to the nearest influent river mouth. 


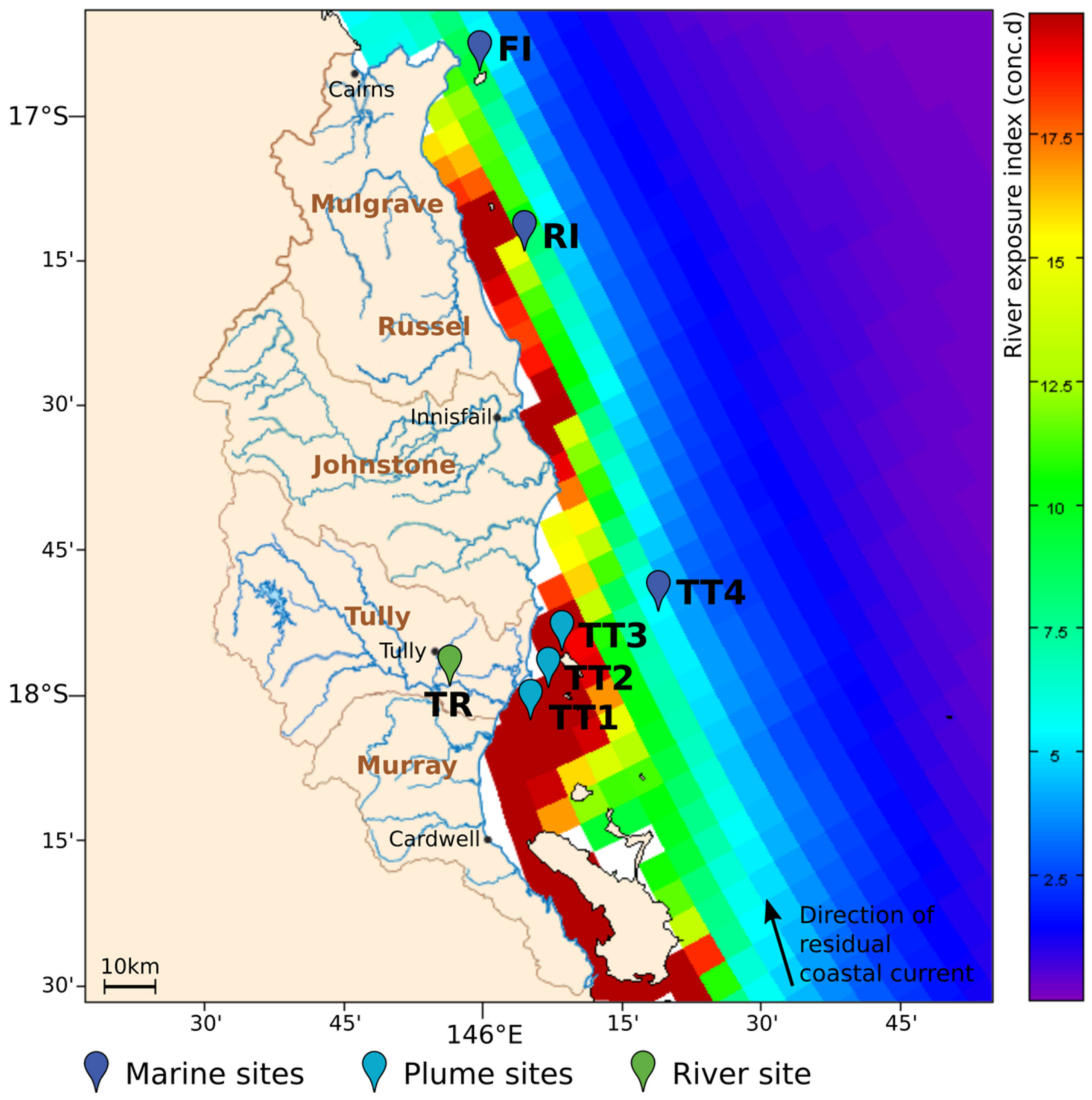


2

Weather in the Tully catchment during the years 2011-13

Figure 2: Weather in the Tully catchment during the years 2011-13: A) temperature and solar exposure, and B) rainfall and river discharge. An average value for the previous week is reported for each day. Dashed lines indicate microbial sampling dates, and the purple line the landfall of tropical cyclone Yasi. The shading represents the extent of the wet season. Sources: BOM, DERM.

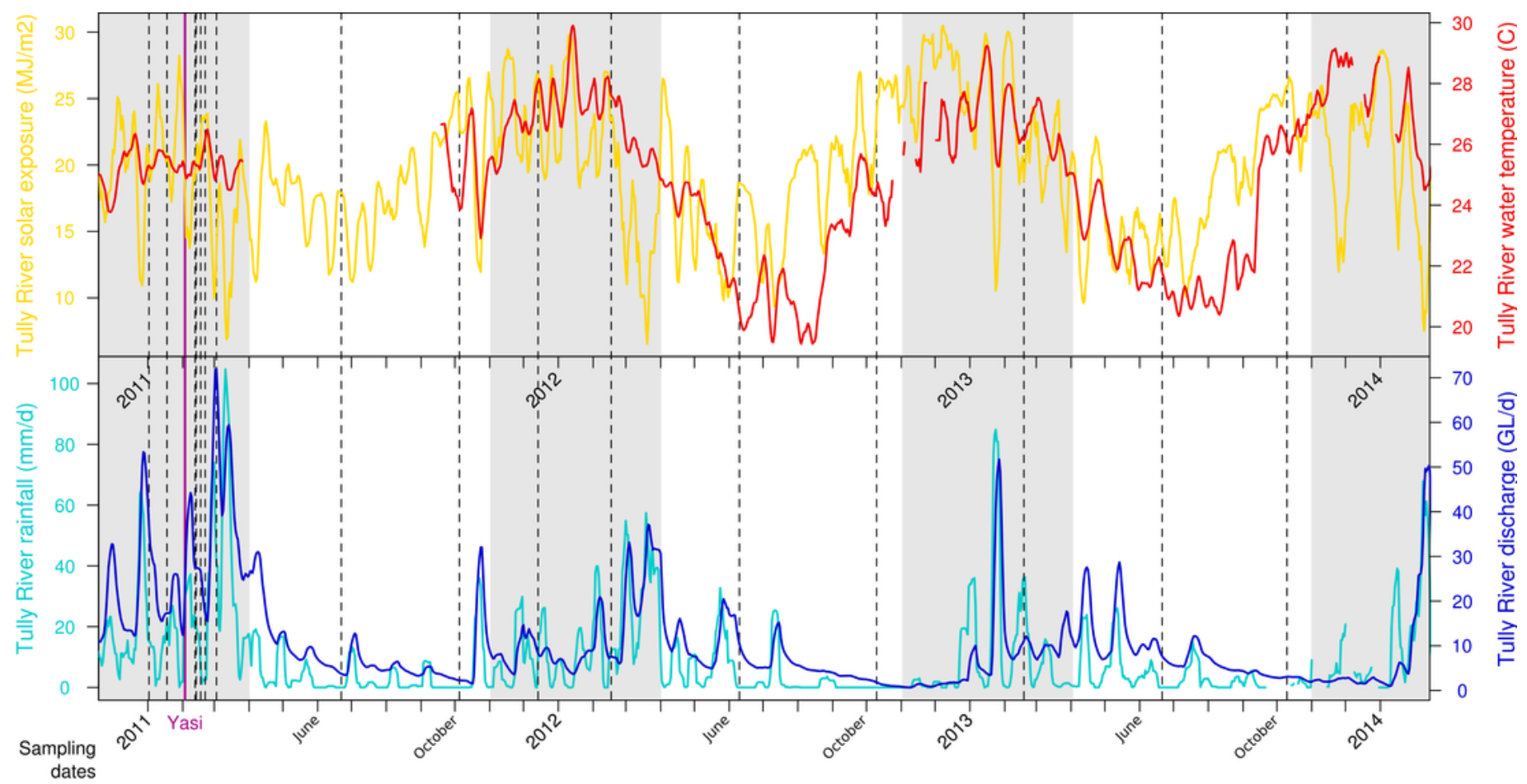




\section{3}

Seasonal and spatial differences in microbial diversity

Figure 3: Boxplot of seasonal (wet or dry) and spatial (three runoff exposure categories) differences in bacterial and archaeal diversity: A) observed OTU richness, B) Shannon-Wiener evenness, C) Shannon-Wiener index. Boxes represent the first quartile, median and third quartile of the data, whiskers the minimum and maximum, and circles the outliers. Blue bars show the statistical comparisons performed and significant differences are represented by a star (Mann-Whitney U test; $p<0.05$ ). 


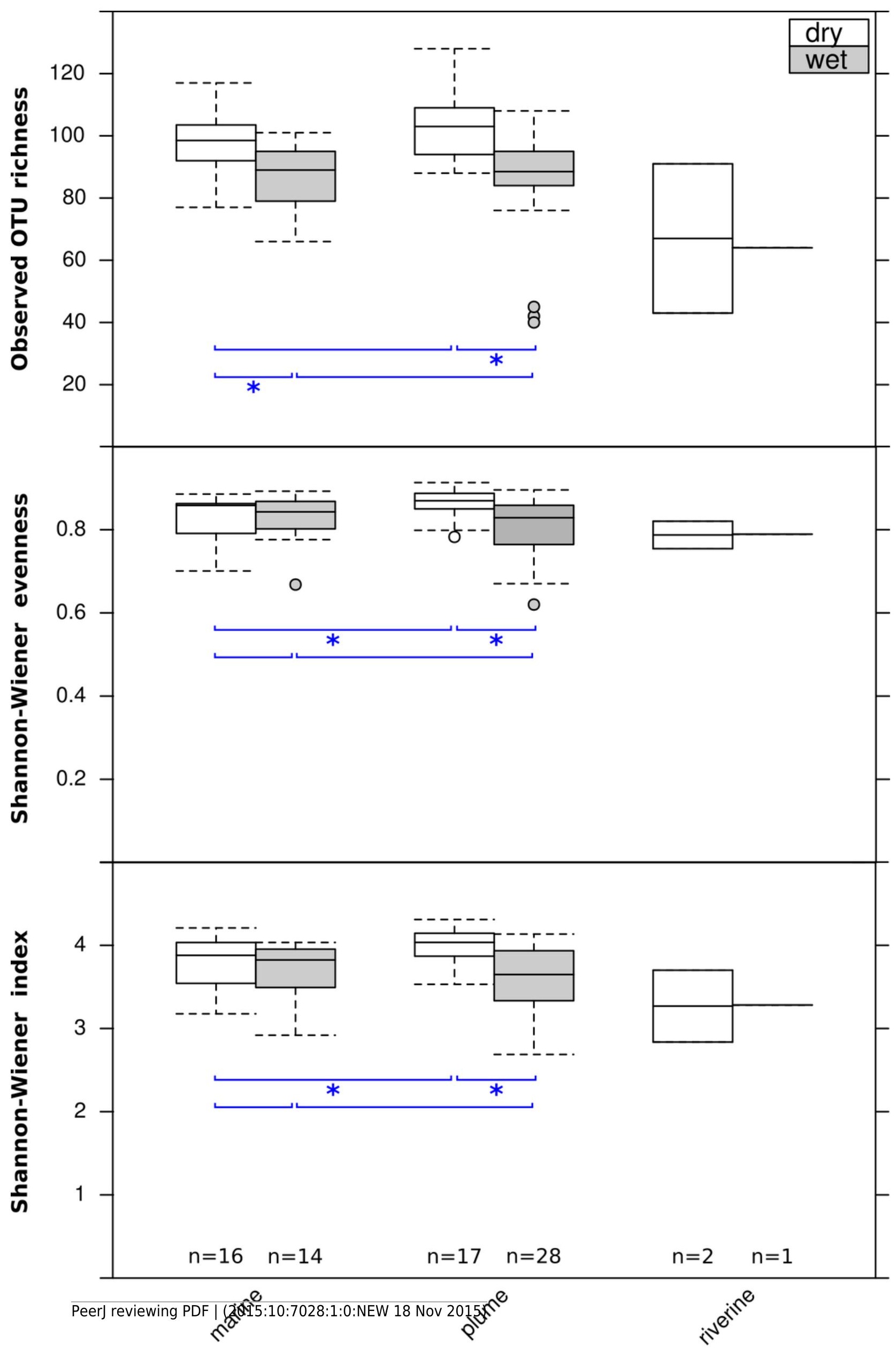


4

Distribution and dynamics of abundant microbial orders for the seven sites surveyed

Figure 4: Distribution and dynamics of abundant microbial orders for the seven sites

surveyed in 2011, 2012 and 2013. Microbial orders present at less than 10\% relative abundance in all samples were omitted. The shading represents the extent of the wet

season.

Relative abundance(\%)

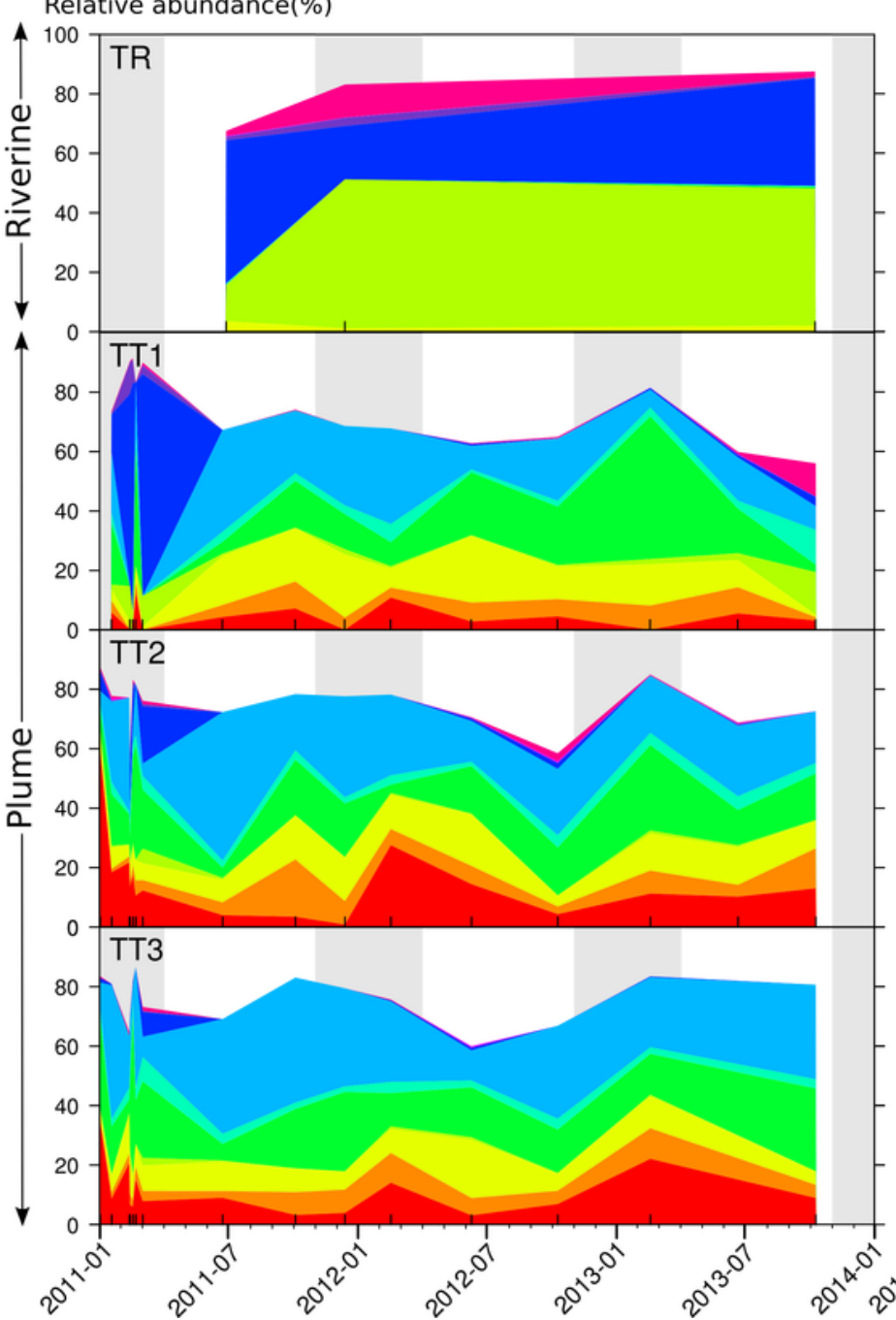

Bacteria; Proteobacteria; Gammaproteobacteria; Xanthomonadales Bacteria; Proteobacteria; Gammaproteobacteria; Enterobacteriales Bacteria; Proteobacteria; Betaproteobacteria; Rhodocyclales Bacteria; Proteobacteria; Betaproteobacteria; Burkholderiales Bacteria; Proteobacteria; Alphaproteobacteria; Rickettsiales

Bacteria; Proteobacteria; Alphaproteobacteria; Rhodospirillales Bacteria; Cyanobacteria; Synechococcophycideae; Synechococcales Bacteria; Bacteroidetes; Sphingobacteriia; Sphingobacteriales

Bacteria; Bacteroidetes; Flavobacteriia; Flavobacteriales

Bacteria; Actinobacteria; Acidimicrobiia; Acidimicrobiales Archaea; Euryarchaeota; Thermoplasmata; E2

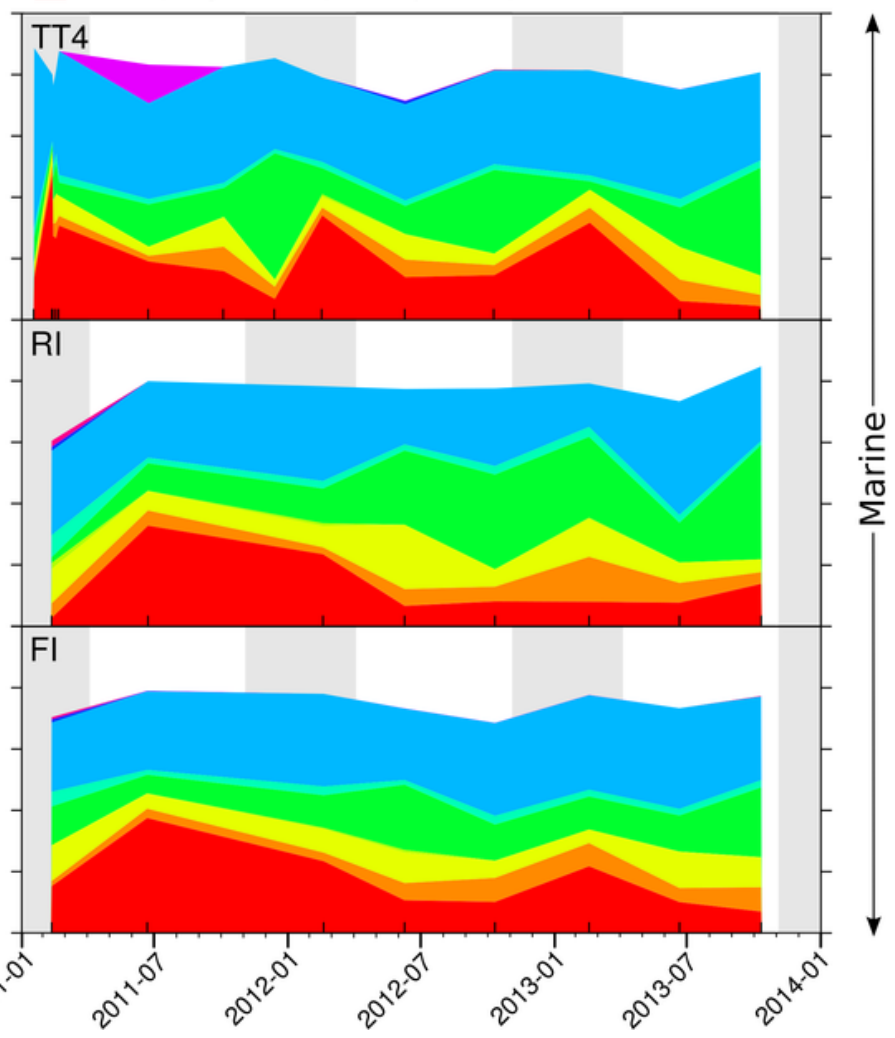




\section{5}

Spatiotemporal organization of microbial communities

Figure 5: PCOA plot showing the spatiotemporal organization of microbial communities based on their Hellinger dissimilarity. Symbol color, shape and size depend on the type of site, season of collection and distance from the Tully River mouth, respectively. The OTUS explaining the largest variation are represented by arrows and their assigned Greengenes ID and genus-level taxonomy is shown. A star indicates indicator OTUs (indicator species analysis; $p<0.05$ ). 


\section{A) All samples}

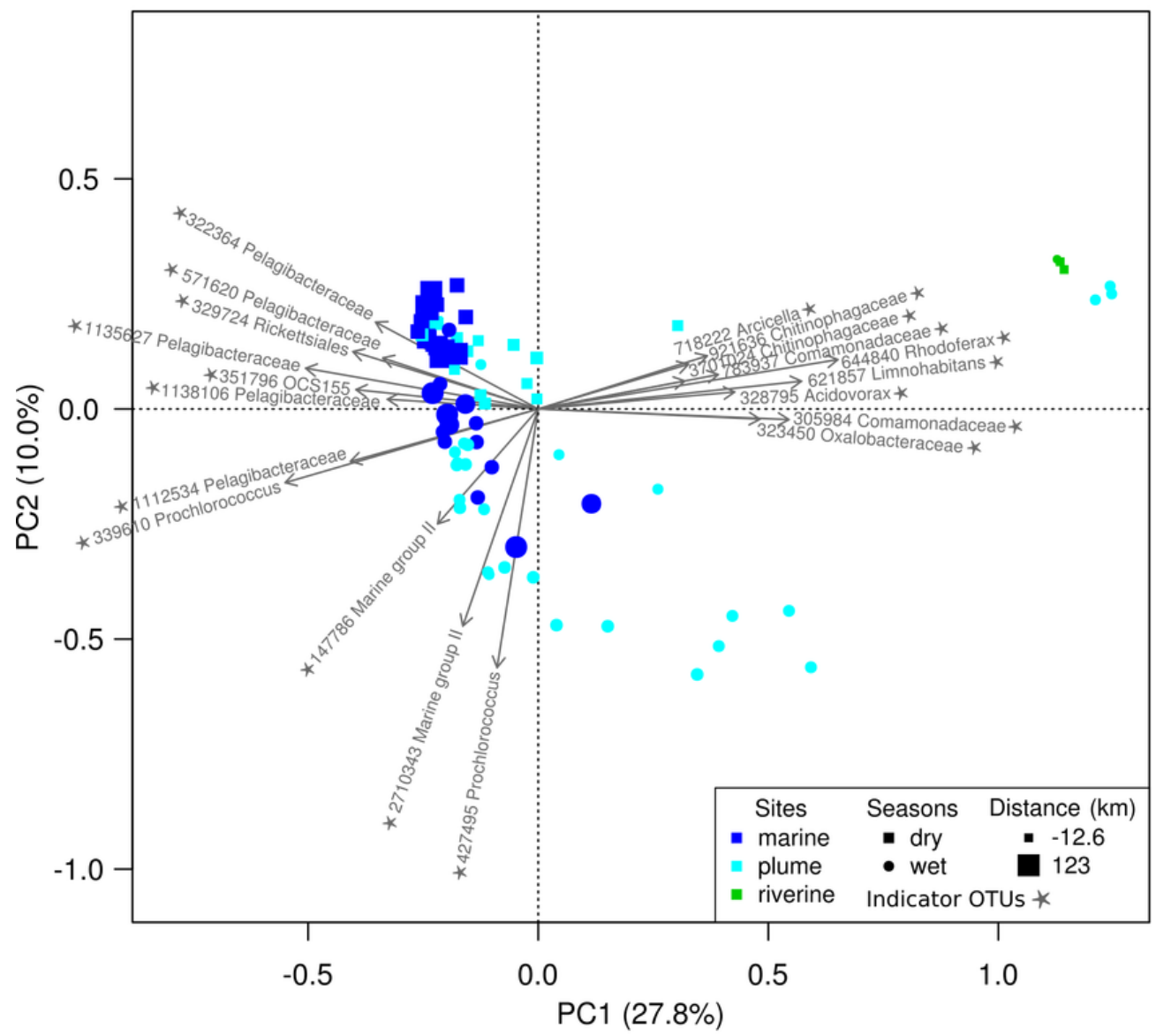

B) Marine samples only

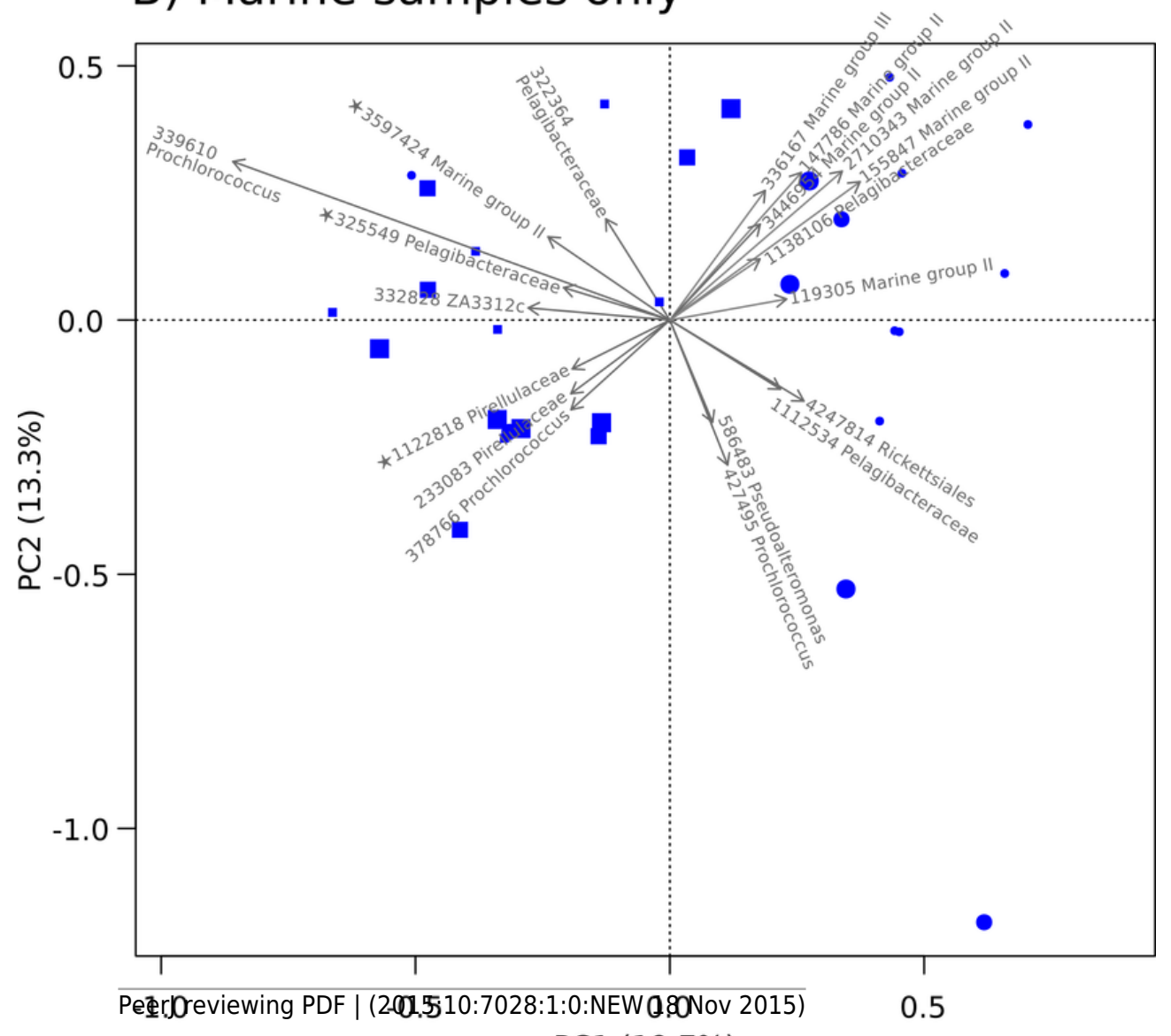

PC1 (19.7\%) 


\section{6}

Relationship between environmental parameters and microbial profiles

Figure 6: RDA plot showing the relationship between GBR environmental parameters and Hellinger-transformed microbial profiles: A) for all environmental factors, and B) with the contribution of salinity removed. Disks represent sampling sites and are colored according to the AIMS water quality index (dark green: very good, green: good, yellow: moderate, orange: poor, red: very poor). OTUs are depicted by red crosses and the genus-level Greengenes taxonomy of the most discriminating ones is shown. The factors explaining sample distribution are represented by blue arrows: rainfall in the last 7 days (rain_7d), water temperature (water_temp), water quality index (water_qual_idx) and salinity. Any significant association is indicated by a star (PERMANOVA; $p<0.05)$. 


\section{A) All factors}

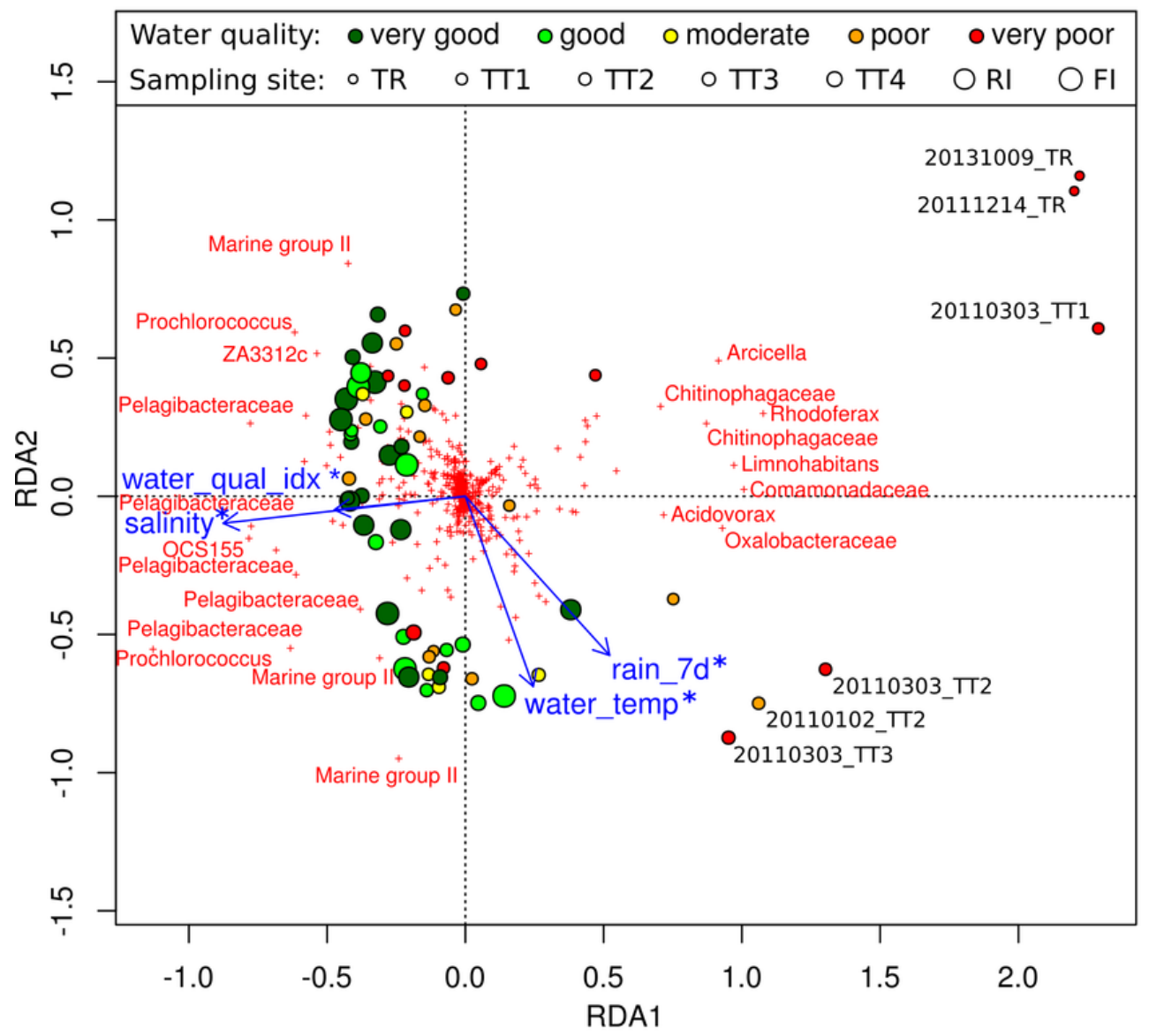

B) Without salinity

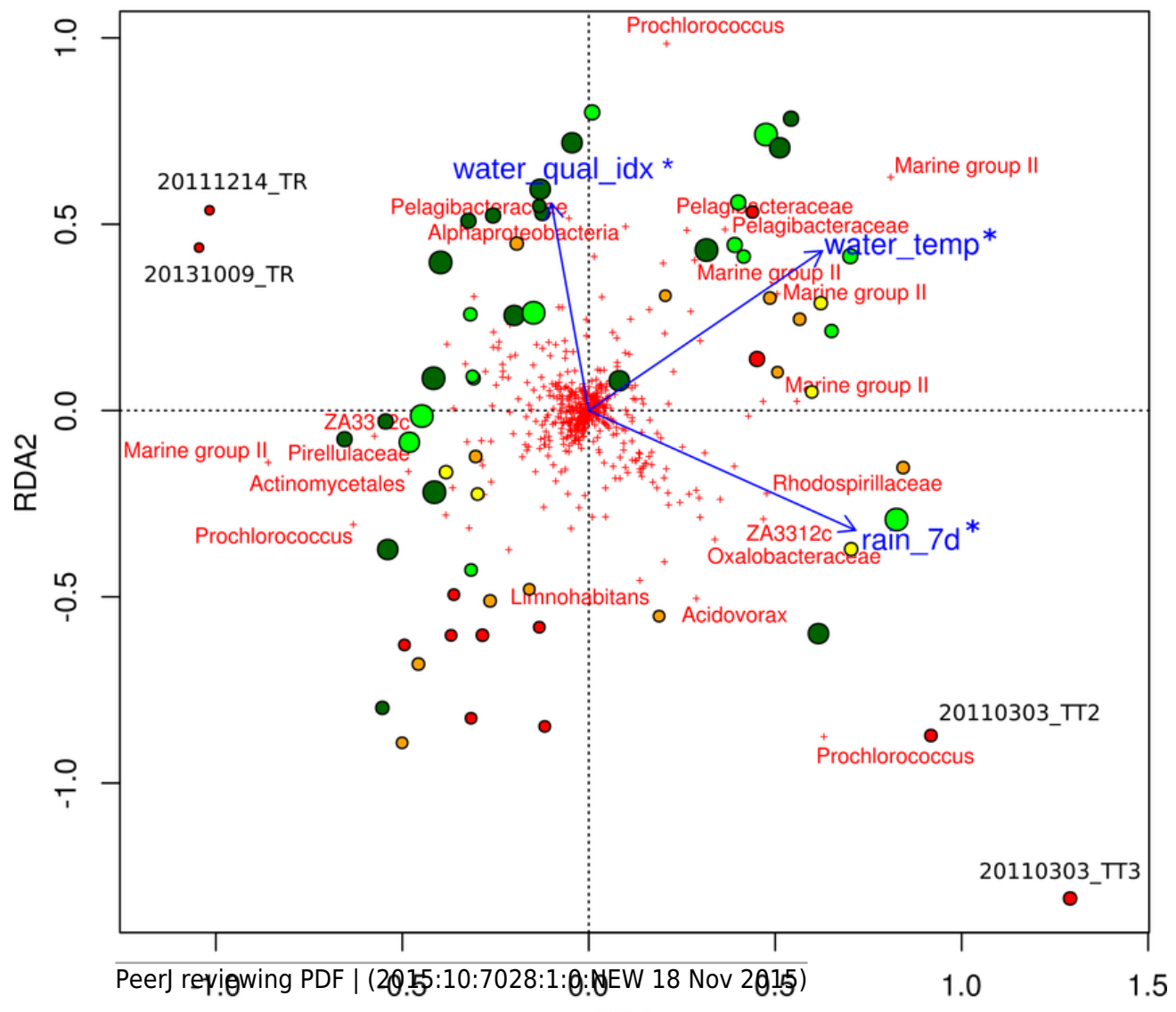

